\title{
Studi Perencanaan Gedung Rektorat Dengan Sistem Rangka Pemikul Momen Khusus (Studi Kasus Unhasy Tebuireng Jombang)
}

\author{
Rectorate Building Planning Study With Special Moment Bearer Frame \\ System (Case Study Unhasy Tebuireng Jombang)
}

\author{
Fadjar Wahyu Rahardjo ${ }^{1}$, Abdiyah Amudi ${ }^{2}$, Titin Sundari ${ }^{3}$, Totok Yulianto ${ }^{4}$ \\ ${ }^{1234}$ Jurusan Teknik Sipil, Fakultas Teknik, Universitas Hasyim Asy'ari Tebuireng Jombang. \\ Email : fadjarwa97@gmail.com
}

\begin{abstract}
Abstrak
Gedung rekorat terletak di lokasi kampus B Universitas Hasyim Asy'ari Tebuireng - Jombang yang difungsikan sebagai pusat akademik dan administrasi semua Fakultas. Rencana peningkatan bangunan gedung rektorat baru terdiri atas 7 lantai dengan ketinggian 32,40 $\mathrm{m}$ dan luas gedung $574 \mathrm{~m}^{2}$. Tujuan utama dilakukan penelitian agar dapat menghasilkan gambar perencanaan struktur gedung rektorat baru.

Perencanaan struktur gedung rektorat baru menggunakan sistem tunggal berupa sistem rangka pemikul momen khusus (SRPMK) dan pemodelan menggunakan program aplikasi untuk menghitung momen dan reaksi dari komponen pelat lantai, tangga, balok, kolom, sloof dan poerplat dengan beban gempa desain menggunakan metode statik ekuivalen. Peraturan yang digunakan untuk perencanaan menggunakan SNI 1726:2012, SNI 2847:2013, SNI 1727:2013 dan PPIUG:1983. Hasil analisis dan desain pada gedung rektorat baru menghasilkan komponen struktur primer berupa balok B1 = 450x600, B3=350x500 dan kolom K1 = $700 x$ 700, K2 = $600 \times 600$ yang telah memenuhi syarat penampang untuk sistem rangka pemikul momen khusus dan mekanisme kolom kuat-balok lemah. Komponen struktur sekunder berupa pelat dengan tebal = $13 \mathrm{~cm}$. Komponen struktur bawah berupa sloof $S L=400 \times 800$ dan poerplat P1 $=2100 \times 2100 \times 650$ serta minipile 35 cm pada kedalaman 14 meter.
\end{abstract}

Kata Kunci: Perencanaan struktur; SRPM; strong column weak beam

\begin{abstract}
The record building is located on the location of the B campus of the Hasyim Asy'ari University Tebuireng Jombang which functions as an academic and administrative center for all faculties. The planned improvement of the new rectorate building consists of 7 floors with a height of $32.40 \mathrm{~m}$ and a building area of $574 \mathrm{~m} 2$. The main purpose of the research is to produce a picture of the structure of the new rector's building.

The new rector's building structure planning uses a single system in the form of a special moment bearing frame system (SRPMK) and modeling uses an application program to calculate the moment and reaction of the components of floor plates, stairs, beams, columns, sloof and poerplat with earthquake load design using the equivalent static method. The regulations used for planning use SNI 1726:2012, SNI 2847:2013, SNI 1727:2013 and PPIUG:1983. The results of analysis and design in the new rectorate building produce primary structural components in the form of beams $B 1=450 \times 600, B 3=350 \times 500$ and columns $K 1=700 \times 700, K 2=600 \times 600$ that have met the cross section requirements for special moment bearing frame systems and the mechanism of the Strong Column Weak Beam. Secondary structural components in the form of plates with thickness $=13 \mathrm{~cm}$. Lower structure components are SLO SL $=400 \times 800$ and template P1 $=2100 \times 2100 \times 650$ and $35 \mathrm{~cm}$ minile at a depth of 14 meters.
\end{abstract}

Keywords: Structural palnning; SRPM; strong column weak beam 


\section{PENDAHULUAN}

Semakin berkembangnya jaman dalam bidang pembangunan khususnya gedung turut meningkat. Perencanaan yang matang guna pembangunan gedung harus memperhatikan banyak faktor dan persyaratan sesuai dengan peraturan SNI, dimana gedung harus mampu tahan terdahap faktor alam yaitu faktor gempa.

Perencanaan bangunan khususnya gedung tahan gempa mengacu pada peraturan SNI 1726:2012 yang didalamnya mengelompokkan jenis gedung berdasarkan tingkat kategori resiko bahaya. Sistem struktur gedung yang mampu menahan beban lateral dan aksial serta momen yang disebabkan karena gempa dapat dipikul oleh suatu sistem yang disebut rangka pemikul momen dengan mekanisme bahwa komponen struktur dan join dapat menahan gaya yang bekerja. Sistem struktur rangka pemikul momen pada gedung terbagi menjadi 3 jenis yaitu berjenis biasa, menengah dan khusus.

Berdasarkan peraturan yang berlaku dalam perencananaan bangunan tahan gempa maka Universitas Hasyim Asy'ari selaku lembaga pendidikan tinggi swasta yang kini tengah berada dalam tahap berkembang yang ditandai dengan meningkatnya sarana dan prasarana berupa pembangunan penambahan gedung perkuliahan pada tahun 2019 dan rencana akan pembangunan gedung rektorat baru pada beberapa tahun kedepan yang harus memperhatikan aspek keamanan dan sistem struktur. Aspek tersebut sangat penting guna meminimalisir terjadinya korban jiwa dan kerusakan pada bangunan. Dengan adanya peningkatan tersebut diharapkan dapat lebih menunjang proses akademik dan administrasi selama kegiatan perkuliahan sehingga dapat terciptanya suasana yang kondusif dan lancar bagi para mahasiswa, dosen dan para pegawai.

Berdasarkan uraian latar belakang, penulis melakukan suatu penelitian berupa studi perencanaan struktur gedung rektorat baru menggunakan sistem rangka pemikul momen berjnis khusus (SRPMK) dengan tujuan agar struktur gedung dapat berperilaku daktail ketika terjadi gempa. Adapun batasan masalah yang diterapkan dalam penelitian yaitu sistem struktur gedung memakai sistem rangka pemikul momen berjenis khusus (SRPMK), pemodelan struktur gedung secara 3D menggunakan program SAP2000v.14, memperhitungkan komponen struktur gedung yang berupa struktur primer; struktur sekunder; struktur pondasi, hubungan antar joint bersifat kaku (rigid), metode gempa rencana menggunakan statik ekuivalen, dan data tanah dari hasil uji sondir dan boring.

\section{TINJAUAN PUSTAKA}

\section{Metode Gempa Statik Ekuivalen}

Metode ini merupakan penyederhanaan dari metode gempa secara dinamik dengan menganggap sebagai beban-beban statik yang bekerja pada tiap lantai gedung dengan menirukan pergerakan tanah dan gaya gempa yang bekerja sebesar $100 \%$ pada sumbu kuat dan 30\% pada sumbu lemah secara bersamaan. Metode ini dapat digunakan pada gedung yang memiliki ketinggian tidak lebih dari 40 meter ataupun 10 lantai dengan memiliki geometri yang beraturan ataupun tipikal yang tertera dalam peraturan SNI 1726:2012 dan SNI 1726:2002.

\section{Simpangan}

Secara umum, simpangan dapat terjadi akibat adanya pengaruh gaya gempa yang diberikan pada struktur gedung yang berada di tiap antar lantai. Skema simpangan dan batasan simpangan ijin antar lantai dapat dilihat pada peraturan SNI 1726:2012.

\section{Prinsip Desain Sistem Rangka SRPMK}

Secara umum, sistem struktur berkonsep SRPMK memiliki tingkat daktilitas yang tinggi sehingga mampu menahan siklus respon inelastis pada saat menerima beban gempa rencana. Mekanisme pada sistem ini yaitu kolom kuat-balok lemah yang bekerja menyebar secara merata pada tiap lantai guna menghindari kegagalan geser pada balok-kolom serta joint.

\section{Komponen Struktur Gedung}

Komponen struktur primer gedung berupa balok dan kolom yang berfungsi sebagai penopang beban lanjutan dan pelat termasuk dalam struktur sekunder pada bangunan gedung yang berfungsi menahan beban mati dan beban hidup. Tiap komponen struktur menghasilkan gaya dalam berupa gaya aksial, gaya momen dan gaya geser yang diperoleh dari analisa output program SAP2000v.14 yang kemudian dihitung berdasarkan dengan teori kapasitas untuk memperoleh momen nominal dari tiap komponen struktur. Komponen struktur pondasi gedung berupa poer plat dan tiang pancang yang berfungsi sebagai penyalur beban dari struktur atas untuk disalurkan ke dalam tanah. Daya dukung tanah harus mencapai pada nilai maksimal yang berupa tanah keras.

1) Daya dukung tanah hasil data sondir

$$
Q_{t p}=\frac{A_{t p} \cdot p_{\text {konus }}}{3}+\frac{O_{t p} \cdot p_{\text {hmb_pelekat }}}{5}
$$


Dimana:

$\mathrm{Q}_{\mathrm{tp}}=$ beban maksimal tiang

$\mathrm{A}_{\mathrm{tp}}=$ luas potongan melintang tiang

$\mathrm{p}_{\mathrm{konus}}=$ tekanan konus hasil sondir

$\mathrm{O}_{\mathrm{tp}}=$ keliling potongan tiang

$\mathrm{p}_{\mathrm{plkt}}=$ jumlah hambatan pelekat

2) Daya dukung tanah hasil data SPT

Daya dukung ujung tiang

$Q_{p}=\frac{q_{p}}{A_{p}}=\frac{3 . N^{\prime}{ }_{60} \cdot 100}{A_{p}}$

$N^{\prime}{ }_{60}=C_{N} \cdot N_{60}$

$C_{N}=\frac{2}{1+\frac{\sigma^{\prime} y}{\sigma \prime_{r}}}$

Daya dukung selimut tiang

$Q_{S}=\left(\frac{100}{50} \cdot N_{S P T}\right) \cdot A_{S}$

Daya dukung tiang

$Q_{u}=\frac{\left(Q_{p}+Q_{s}\right)}{3}$

\section{METODE}

\section{Tahapan Penelitian}

Tahapan penelitian untuk studi perencanaan struktur Gedung Rektorat Baru Universitas Hasyim Asy'ari dapat dilihat pada Gambar 1 berikut.

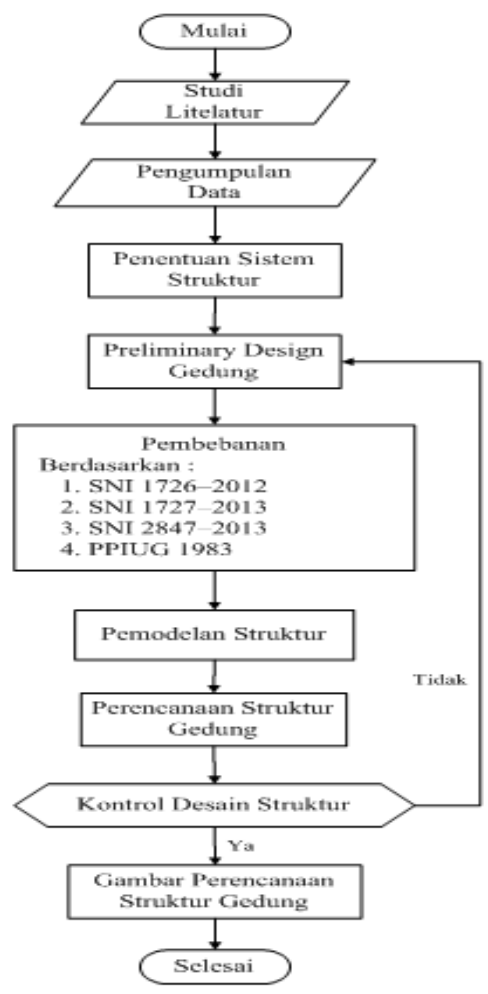

Gambar 1. Diagram Alir Penelitian

\section{Pengumpulan Data}

Data pendukung yang digunakan dalam penelitian sebagai berikut:

1) Data tanah

Data tanah didapatkan dari hasil pengujian sondir yang dapat dilihat pada Tabel 1 berikut.

Tabel 1. Data Tanah

\begin{tabular}{ccccc}
\hline $\begin{array}{c}\mathrm{Z} \\
(\mathrm{m})\end{array}$ & $\begin{array}{c}\text { Konus } \\
\text { Min }\end{array}$ & $\begin{array}{c}\text { Qp } \\
(\mathrm{kg})\end{array}$ & $\begin{array}{c}\text { Qs } \\
(\mathrm{kg})\end{array}$ & $\begin{array}{c}\text { Q.ijin } \\
(\mathrm{ton})\end{array}$ \\
\hline 4,00 & 55,00 & $56.341,36$ & $31.751,61$ & 29,36 \\
\hline 5,00 & 25,00 & $54.878,80$ & $43.818,22$ & 32,90 \\
\hline 6,00 & 50,00 & $59.139,12$ & $57.954,98$ & 39,03 \\
\hline 7,00 & 45,00 & $73.208,03$ & $67.059,60$ & 46,76 \\
\hline 8,00 & 90,00 & $79.750,51$ & $77.559,63$ & 52,44 \\
\hline 9,00 & 50,00 & $79.497,85$ & $85.404,20$ & 54,97 \\
\hline 10,00 & 30,00 & $81.383,57$ & $97.975,63$ & 59,79 \\
\hline 11,00 & 60,00 & $81.987,49$ & $107.027,06$ & 63,00 \\
\hline 12,00 & 40,00 & $72.741,74$ & $118.089,92$ & 63,61 \\
\hline 13,00 & 46,00 & $81.449,98$ & $128.247,63$ & 69,90 \\
\hline 14,00 & 166,67 & $98.047,56$ & $135.790,49$ & 77,95 \\
\hline \multicolumn{5}{l}{ Sumber: Hasil Uji Sondir $(2018)$} \\
\end{tabular}

\section{Preliminary Desain}

Dimensi serta mutu bahan pada struktur gedung yang digunakan untuk penelitian dapat dilihat pada Tabel 2 berikut.

Tabel 2. Dimensi Komponen Struktur

\begin{tabular}{lcc}
\hline $\begin{array}{c}\text { Komponen } \\
\text { Struktur }\end{array}$ & $\begin{array}{c}\text { Dimensi } \\
(\mathrm{mm})\end{array}$ & $\begin{array}{c}\text { Mutu Bahan } \\
\text { (MPa) }\end{array}$ \\
\hline $\begin{array}{l}\text { Pelat } \\
\text { a. Lantai }\end{array}$ & 130 & 25 \\
b. Atap & 100 & \\
\hline $\begin{array}{l}\text { Balok Induk } \\
\text { c. B1 } \\
\text { d. B3 }\end{array}$ & $\begin{array}{l}450 / 600 \\
350 / 500\end{array}$ & 30 \\
\hline $\begin{array}{l}\text { Balok Anak (B2) } \\
\text { Balok Kantilever } \\
\text { (B4) }\end{array}$ & $300 / 450$ & 30 \\
\hline Balok Tepi (B5) & $250 / 450$ & 30 \\
\hline $\begin{array}{l}\text { Kolom } \\
\text { a. K1 } \\
\text { b. K2 }\end{array}$ & $\begin{array}{l}700 / 700 \\
600 / 600\end{array}$ & 30 \\
\hline Sloof (SL) & $400 / 800$ & 30 \\
\hline Sumber: Penelitian Penulis (2019)
\end{tabular}

\section{Pembebanan}

Asumsi nilai pembebanan yang digunakan dalam penelitian antara lain:

1) Beban mati
Bj beton bertulang
Bj beton
Bj pasir
Pasangan bata merah
Dinding partisi
Plafond-penggantung

$$
\begin{aligned}
& =2400,00 \mathrm{~kg} / \mathrm{m}^{3} \\
& =2200,00 \mathrm{~kg} / \mathrm{m}^{3} \\
& =1800,00 \mathrm{~kg} / \mathrm{m}^{3} \\
& =250,00 \mathrm{~kg} / \mathrm{m}^{2} \\
& =80,00 \mathrm{~kg} / \mathrm{m}^{2} \\
& =18,00 \mathrm{~kg} / \mathrm{m}^{2}
\end{aligned}
$$

Proteksi/Desember 2020 Volume 2 No. 2 

Mekanikal elektrikal
$=25,00 \mathrm{~kg} / \mathrm{m}^{2}$
Lapisan waterproofing
$=14,00 \mathrm{~kg} / \mathrm{m}^{2}$

2) Beban hidup
Beban guna lantai
$=250,00 \mathrm{~kg} / \mathrm{m}^{2}$
Beban guna lantai atap
$=100,00 \mathrm{~kg} / \mathrm{m}^{2}$

Kombinasi pembebanan yang digunakan dalam analisis penelitian dapat dilihat pada Tabel 3 berikut.

Tabel 3. Kombinasi Pembebanan

\begin{tabular}{|c|c|c|}
\hline Tipe & Kombinasi & Keterangan \\
\hline & $1,4 \mathrm{D}+1,4 \mathrm{SDL}$ & \multirow{2}{*}{$\begin{array}{c}\text { Pembebanan } \\
\text { Tetap }\end{array}$} \\
\hline $\mathrm{U} 2$ & $1,2 \mathrm{D}+1,2 \mathrm{SDL}+1,6 \mathrm{LL}$ & \\
\hline U3 & $1,2 \mathrm{D}+1,2 \mathrm{SDL}+0,5 \mathrm{LL}+1 \mathrm{EQx}$ & \multirow{8}{*}{$\begin{array}{c}\text { Pembebanan } \\
\text { Sementara }\end{array}$} \\
\hline U4 & 1,2D+1,2SDL+0,5LL-1EQx & \\
\hline U5 & $1,2 \mathrm{D}+1,2 \mathrm{SDL}+0,5 \mathrm{LL}+1 \mathrm{EQy}$ & \\
\hline U6 & 1,2D+1,2SDL+0,5LL-1EQy & \\
\hline U7 & $0,9 \mathrm{D}+0,9 \mathrm{SDL}+1 \mathrm{EQx}$ & \\
\hline U8 & 0,9D+0,9SDL-1EQx & \\
\hline U9 & $0,9 \mathrm{D}+0,9 \mathrm{SDL}+1 \mathrm{EQy}$ & \\
\hline U10 & $0,9 \mathrm{D}+0,9 \mathrm{SDL}-1 \mathrm{EQy}$ & \\
\hline
\end{tabular}

Sumber: Penelitian Penulis (2019)

\section{Pemodelan Struktur}

Pemodelan struktur gedung pada penelitian menggunakan program SAP2000v.14 yang dapat dilihat pada Gambar 2, Gambar 3 dan Gambar 4.

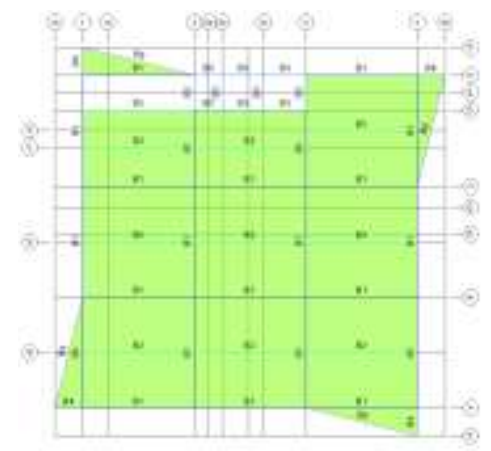

Gambar 2. Denah Struktur Gedung

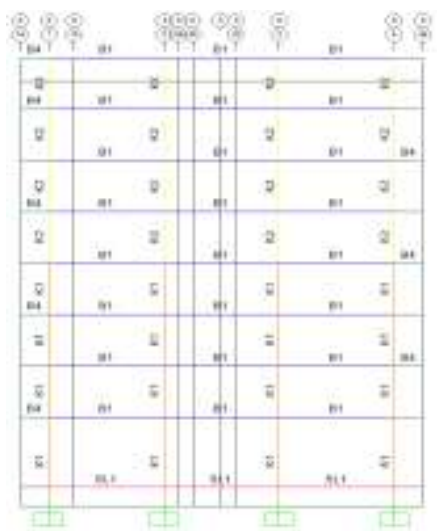

Gambar 3. Portal Struktur Gedung

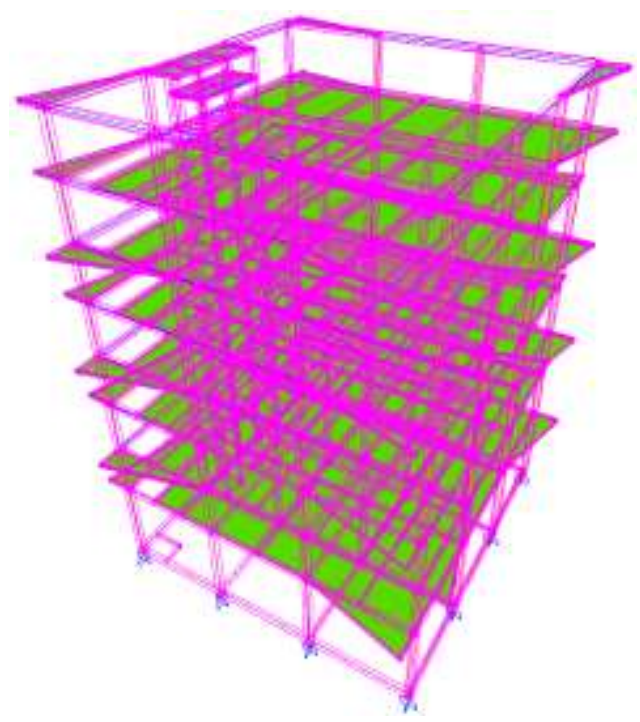

Gambar 4. Pemodelan 3D Struktur Gedung

Aspek teknis yang digunakan dalam perencanaan struktur gedung rektorat baru dapat dilihat pada Tabel 4 berikut.

Tabel 4. Aspek Teknis

\begin{tabular}{l|l}
\hline \multicolumn{1}{c|}{ Item } & \multicolumn{1}{|c}{ Keterangan } \\
\hline Bangunan & Gedung rektorat baru \\
\hline Fungsi bangunan & $\begin{array}{l}\text { Pusat akademik dan administrasi } \\
\text { seluruh fakultas }\end{array}$ \\
\hline Lokasi bangunan & Jalan irian jaya no.55 tebuireng \\
\hline Koordinat lokasi & $\begin{array}{l}-7.60914256315409 \text { (lintang) } \\
112.2344183921814 \text { (bujur) }\end{array}$ \\
\hline Jumlah lantai & 7 lantai \\
\hline Panjang bangunan & 24 meter \\
\hline Lebar bangunan & 24 meter \\
\hline Elevasi lantai & 4,05 meter tiap lantai \\
\hline Jarak antar kolom & 8 meter, 3 meter, dan 2 meter \\
\hline Tipe struktur & $\begin{array}{l}\text { Beton bertulang (25 MPa dan 30 } \\
\text { MPa) }\end{array}$ \\
\hline Sistem struktur & $\begin{array}{l}\text { Sistem rangka pemikul momen } \\
\text { jenis khusus (SRPMK) }\end{array}$ \\
\hline Gempa rencana & Statik ekuivalen \\
\hline $\begin{array}{l}\text { Mutu tulangan ulir } \\
\text { (D) }\end{array}$ & 400 MPa \\
\hline $\begin{array}{l}\text { Mutu tulangan polos } \\
\text { (Ø) }\end{array}$ & 240 MPa \\
\hline Sumber: Penelitian Penuls (2019)
\end{tabular}

Sumber: Penelitian Penulis (2019)

\section{HASIL DAN PEMBAHASAN}

\section{Analisis Gempa}

Deformasi pada gedung yang diakibatkan oleh beban gempa rencana berupa gempa statik ekuivalen dapat dilihat pada Gambar 5 dan Gambar 6. 


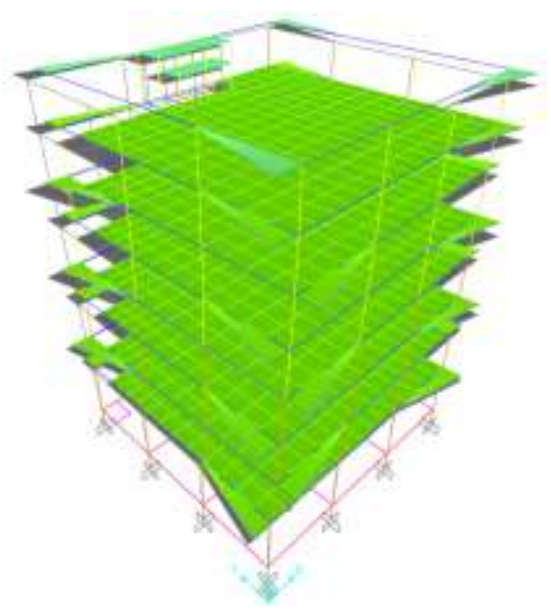

Gambar 5. Deformasi Gedung Akibat Gempa (EQ) Arah-x

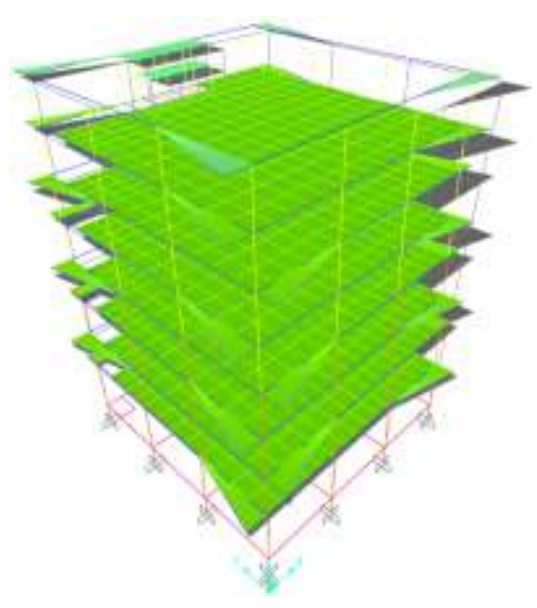

Gambar 6. Deformasi Gedung Akibat Gempa (EQ) Arah-y

Pengecekan simpangan yang terjadi antar lantai gedung akibat gempa rencana dapat dilihat pada Tabel 5 dan Tabel 6.

Tabel 5. Kontrol Simpangan Arah-X

\begin{tabular}{ccccccc}
\hline Lt & Hsx & Joint & $\begin{array}{c}\text { Hasil } \\
\text { SAP }\end{array}$ & $\Delta \mathrm{i}$ & $\Delta \mathrm{a}$ & Ket \\
\hline Atap & 4050 & 314 & 54,32 & 13,00 & 81,00 & Aman \\
\hline 7 & 4050 & 258 & 51,88 & 23,16 & 81,00 & Aman \\
\hline 6 & 4050 & 218 & 47,91 & 31,73 & 81,00 & Aman \\
\hline 5 & 4050 & 178 & 42,19 & 39,28 & 81,00 & Aman \\
\hline 4 & 4050 & 138 & 35,08 & 44,43 & 81,00 & Aman \\
\hline 3 & 4050 & 97 & 27,46 & 44,65 & 81,00 & Aman \\
\hline 2 & 4050 & 53 & 19,33 & 45,56 & 81,00 & Aman \\
\hline 1 & 4050 & 12 & 10,97 & 59,10 & 81,00 & Aman \\
\hline Sloof & 1000 & 336 & 0,08 & 0,45 & 20,00 & Aman \\
\hline
\end{tabular}

Sumber: Hasil Pengolahan Data (2019)
Tabel 6. Kontrol Simpangan Arah-y

\begin{tabular}{ccccccc}
\hline Lt & Hsx & Joint & $\begin{array}{c}\text { Hasil } \\
\text { SAP }\end{array}$ & $\Delta \mathbf{i}$ & $\Delta \mathbf{a}$ & Ket \\
\hline Atap & 1850 & 321 & 62,08 & 7,17 & 37,00 & Aman \\
\hline $\begin{array}{c}\text { Atap } \\
\text { lift }\end{array}$ & 220 & 300 & 60,70 & 10,79 & 44,00 & Aman \\
\hline 7 & 4050 & 271 & 58,79 & 28,23 & 81,00 & Aman \\
\hline 6 & 4050 & 231 & 53,98 & 37,41 & 81,00 & Aman \\
\hline 5 & 4050 & 191 & 47,31 & 45,72 & 81,00 & Aman \\
\hline 4 & 4050 & 151 & 39,12 & 51,35 & 81,00 & Aman \\
\hline 3 & 4050 & 111 & 30,38 & 51,65 & 81,00 & Aman \\
\hline 2 & 4050 & 63 & 21,14 & 51,89 & 81,00 & Aman \\
\hline 1 & 4050 & 23 & 11,77 & 64,26 & 81,00 & Aman \\
\hline Sloof & 1000 & 349 & 0,09 & 0,48 & 20,00 & Aman \\
\hline Sum
\end{tabular}

Sumber: Hasil Pengolahan Data (2019)

Dari data hasil simpangan antar lantai gedung yang terjadi menunjukkan bahwa penampang balok dan kolom telah memenuhi mekanisme yang diharapkan yaitu strong coloumn-weak beam terhadap beban gempa rencana dengan ditandai dari hasil simpangan ijin hitung $(\Delta \mathrm{i})$ tidak melebihi dari batas simpangan ijin $(\Delta a)$.

\section{Perhitungan Pelat}

Struktur pelat turut dimodelkan dengan kesatuan gedung menggunakan program SAP2000v.14 dan diasumsikan pelat bekerja sebagai diafragma ketika terjadi gempa. Mutu tulangan yang digunakan dalam perencanaan yaitu 240Mpa. Pelat lantai berjenis pelat satu arah (S1) secara tipikal pada tiap lantai dengan tebal $130 \mathrm{~mm}$ menghasilkan tulangan $\varnothing 10-100$ pada tumpuan, Ø10-125 pada lapangan dan $\varnothing 10-300$ sebagai tulangan susut. Sedangkan pelat atap berjenis pelat dua arah (S2) dengan tebal $100 \mathrm{~mm}$ menghasilkan tulangan arah- $\mathrm{x}=$ arah-y pada tumpuan Ø10-150 dan pada lapangan Ø10-150.

\section{Perhitungan Tangga}

Struktur tangga dimodelkan secara terpisah pada struktur utama gedung menggunakan program SAP2000v.14 yang terdapat pada tiap lantai dengan bentuk tangga yaitu U. Data perencanaan tangga yaitu sebagai berikut:

1. Panjang pelat tangga- $1=900,00 \mathrm{~mm}$

2. Lebar pelat tangga-1 $=1680,00 \mathrm{~mm}$

3. Panjang pelat tangga- $2=4500,00 \mathrm{~mm}$

4. Lebar pelat tangga-2 $=1500,00 \mathrm{~mm}$

5. Panjang pelat bordes $=1500,00 \mathrm{~mm}$

6. Lebar pelat bordes $\quad=1680,00 \mathrm{~mm}$

7. Tinggi bordes pertama $=660,00 \mathrm{~mm}$

8. Tinggi bordes kedua $=2720,00 \mathrm{~mm}$

9. Tanjakan/optrede $=170,00 \mathrm{~mm}$

10. Injakan/antrede $\quad=300,00 \mathrm{~mm}$

11. Tebal pelat tangga $=120,00 \mathrm{~mm}$

12. Tebal pelat bordes $\quad=\quad 120,00 \mathrm{~mm}$

13. Sudut miring tangga $=29,54^{\circ}$ 
Mutu tulangan dan mutu bahan yang digunakan yaitu $240 \mathrm{MPa}$ dan $25 \mathrm{MPa}$. Pelat tangga menghasilkan tulangan utama Ø10-125 dan tulangan bagi Ø8-250. Sedangkan pelat bordes menghasilkan tulangan utama Ø10-125 pada arah-x dan arah-y.

\section{Perhitungan Balok}

Mutu tulangan yang digunakan yaitu $400 \mathrm{MPa}$ sebagai tulangan lentur dan $240 \mathrm{MPa}$ sebagai tulangan geser. Rekapitulasi penulangan balok dapat dilihat pada Tabel 7 dan Tabel 8.

Tabel 7. Rekapitulasi Penulangan Lentur Balok

\begin{tabular}{ccccccc}
\multirow{2}{*}{ Tipe } & \multirow{2}{*}{$\begin{array}{c}\text { Ket } \\
(\mathrm{cm})\end{array}$} & Torsi & \multicolumn{2}{c}{ Tumpuan } & \multicolumn{2}{c}{ Lapangan } \\
\cline { 4 - 7 } & & \multicolumn{2}{c}{ Atas } & Bawah & Atas & Bawah \\
\hline B1 & $45 / 60$ & 4D12 & 10D19 & 5D19 & 5D19 & 7D19 \\
\hline B2 & $30 / 45$ & - & 4D19 & 2D19 & 2D19 & 2D19 \\
\hline B3 & $35 / 50$ & 2D12 & 5D19 & 3D19 & 3D19 & 3D19 \\
\hline B4 & $25 / 45$ & 2D12 & 3D19 & 2D19 & 2D19 & 2D19 \\
\hline B5 & 25/30 & 2Ø10 & 3D16 & 2D16 & 2D16 & 2D16 \\
\hline
\end{tabular}

Sumber: Hasil Pengolahan Data (2019)

Tabel 8. Rekapitulasi Penulangan Geser Balok

\begin{tabular}{ccc} 
Tipe & Tumpuan & Lapangan \\
\hline B1 & $\varnothing 10-100$ & $\varnothing 10-120$ \\
\hline B2 & $\varnothing 10-100$ & $\varnothing 10-150$ \\
\hline B3 & $\varnothing 10-100$ & $\varnothing 10-150$ \\
\hline B4 & $\varnothing 10-100$ & $\varnothing 10-150$ \\
\hline B5 & $\varnothing 10-100$ & $\varnothing 10-130$
\end{tabular}

Sumber: Hasil Pengolahan Data (2019)

\section{Perhitungan Kolom}

Mutu tulangan yang digunakan yaitu $400 \mathrm{MPa}$ sebagai tulangan utama dan $240 \mathrm{MPa}$ sebagai tulangan geser. Rekapitulasi penulangan kolom dapat dilihat pada Tabel 9.

Tabel 9. Rekapitulasi Penulangan Kolom

\begin{tabular}{lcccc}
\hline & \multirow{2}{*}{$\begin{array}{c}\text { Ket } \\
\text { Tipe }\end{array}$} & Tul. & \multicolumn{2}{c}{ Tul.Geser } \\
\cline { 4 - 5 } & & Utama & Tumpuan & Lapangan \\
\hline K1 & $70 / 70$ & $16 \mathrm{D} 19$ & $\varnothing 10-100$ & $\emptyset 10-130$ \\
\hline K2 & $60 / 60$ & 12 D19 & $\varnothing 10-100$ & $\emptyset 10-130$ \\
\hline
\end{tabular}

Sumber: Hasil Pengolahan Data (2019)

\section{Perhitungan Sloof}

Mutu tulangan yang digunakan yaitu $400 \mathrm{MPa}$ sebagai tulangan utama dan $240 \mathrm{MPa}$ sebagai tulangan geser dengan dimensi 400/800 (mm). Penulangan utama pada daerah tumpuan bagian atas = bawah yaitu 6D19, pada daerah lapangan bagian atas = bawah yaitu 6D19 dan untuk torsi dipakai 4D12. Sedangkan penulangan geser pada daerah tumpuan Ø10-100 dan pada daerah lapangan Ø10120.

\section{Perhitungan Pondasi}

Struktur pondasi yang direncanakan berupa poer plat yang terletak pada kedalaman 1,00 meter dari muka tanah asli dan mini pile pada kedalaman 14 meter. Mutu tulangan dan bahan yang digunakan poer plat yaitu $400 \mathrm{MPa}$ dan $30 \mathrm{MPa}$ dengan dimensi 2100x2100x650 (mm). Sehingga menghasilkan tulangan utama arah-x = arah-y yaitu D16-150 dengan jumlah mini pile berjumlah 9 buah. Spesifikasi mini pile yang digunakan sebagai berikut:
1. Tipe
$=$ kotak
2. Jenis
3. Mutu bahan
$=$ prategang
4. Ukuran
$=\mathrm{K}-500 \mathrm{~kg} / \mathrm{cm}^{2}$
$=35 \times 35(\mathrm{~cm})$
5. Daya dukung rencana $=110$ ton (1 tiang)
6. Tulangan utama $=4 \mathrm{D} 3 / 8$ (inch)

Sehingga dengan 9 buah tiang menghasilkan daya dukung kelompok 600,31 ton yang telah lebih besar dari total beban vertikal 573,46 ton dengan tiap 1 tiang menopang beban 84,21 ton yang tidak melebihi dari daya dukung rencana 110 ton.

\section{SIMPULAN}

Persyaratan mekanisme Strong Column Weak Beam telah terpenuhi yang dapat dilihat dari beberapa kondisi yaitu: simpangan antar yang terjadi antar lantai tidak melebihi dari simpangan ijin yang ada dan kondisi balok utama - kolom utama telah memenuhi nilai $\sum \mathrm{M}_{\mathrm{nc}} \geq(1,2) \sum \mathrm{M}_{\mathrm{nb}}$ dimana jumlah kuat lentur nominal kolom lebih besar dari jumlah kuat lentur nominal balok.

Komponen struktur mampu dalam menahan beban gempa rencana yaitu statik ekuivalen dengan menghasilkan dimensi sebagai berikut:

a. Tebal pelat lantai $130 \mathrm{~mm}$ dan pelat atap $100 \mathrm{~mm}$ dengan mutu beton $25 \mathrm{MPa}$ dan mutu tulangan 240MPa.

b. Tipe balok dengan mutu beton $30 \mathrm{MPa}$ dan mutu tulangan $400 \mathrm{MPa}$ serta $240 \mathrm{MPa}$.

1) $\mathrm{B} 1=450 \times 600(\mathrm{~mm})$

2) $\mathrm{B} 2=300 \times 450(\mathrm{~mm})$

3) $\mathrm{B} 3=350 \times 500(\mathrm{~mm})$

4) $\mathrm{B} 4=250 \times 450(\mathrm{~mm})$

5) $\mathrm{B} 5=250 \times 300(\mathrm{~mm})$

c. Tipe kolom dengan mutu beton $30 \mathrm{MPa}$ dan mutu tulangan $400 \mathrm{MPa}$ serta $240 \mathrm{MPa}$.

1) $\mathrm{K} 1=700 \times 700(\mathrm{~mm})$

2) $K 2=600 \times 600(\mathrm{~mm})$

d. Sloof dimensi $400 \times 800(\mathrm{~mm})$ dengan mutu beton $30 \mathrm{MPa}$ dan mutu tulangan $400 \mathrm{MPa}$ serta 240MPa.

e. Poer plat dimensi $2100 \times 2100 \times 650(\mathrm{~mm})$ dengan mutu beton $30 \mathrm{MPa}$ serta mutu tulangan $400 \mathrm{MPa}$ dan mini pile berjumlah 9 pada kedalaman 14 meter.

Proteksi/Desember 2020 Volume 2 No. 2 


\section{REFERENSI}

ATC-40. 1996. Seismic Evaluation and Retrofit of Concrete Building, California: Seismic Safety Commission.

BSN. 2012. SNI 1726:2012 Tata Cara Perencanaan Ketahanan Gempa Untuk Struktur Bangunan Gedung dan Non Gedung, Jakarta: ICS.

BSN. 2013. SNI 1727:2013 Beban Minimum Untuk Perancangan Bangunan Gedung dan Struktur Lain, Jakarta: ICS.

BSN. 2013. SNI 2847:2013 Persyaratan Beton Struktural Untuk Bangunan Gedung, Jakarta: ICS.

DPMB. 1983. PPIUG:1983 Peraturan Pembebanan Indonesia Untuk Gedung, Bandung: Direktorat Penyelidikan Masalah Bangunan.
Nawy, E. G. 1998. Beton Bertulang: Suatu Pendekatan Dasar, Bandung: PT Refika Aditama.

Pamungkas, A., \& Harianti, E. 2013. Desain Pondasi Tahan Gempa, Yogyakarta: ANDI.

Suharjanto. 2013. Rekayasa Gempa Dilengkapi Dengan Analisis Beban Gempa Sesuai SNI 1726:2002, Yogyakarta: Kepel Press.

Virgiansyah, G. 2018. Skripsi: Perencanaan Struktur Gedung Perkuliahan 8 Lantai Di Kabupaten Jember Menggunakan SRPMK, Jember: Teknik Sipil Fakultas Teknik Universitas Jember.

Wigroho, H. Y. 2001. Analisis dan Perancangan Struktur Frame Menggunakan SAP2000. Yogyakarta:ANDI. 